\title{
О ВЛИЯНИИ ФАЦИАЛЬНЫХ ИЗМЕНЕНИЙ ПРИ НАКОПЛЕНИИ СЛОЕВ ПРОМЫШЛЕННОЙ ПАЧКИ КУКЕРСИТА НА ХИМИЧЕСКУЮ СТРУКТУРУ КЕРОГЕНА
}

Геологи и палеонтологи неоднократно отмечали, что промышленная пачка кукерситных сланцев накоплялась в неодинаковых фациальных условиях [']

Органическое вещество кукерсита эстонских месторождений (в ненарушенных зонах) как по стратиграфическому разрезу, так и по простиранию имеет одинаковый элементарный состав $\left[{ }^{2-4}\right]$. Окислительная деструкция концентрата керогена кукерсита слоя $B$ или товарного сланца III сорта $(0-25$ мм) как щелочным перманганатом калия, так и азотной кислотой дает одинаковые ряды насыщенных моно-, ди- и трикарбоновых кислот. На первый взгляд это позволяет считать кероген кукерсита идентичным для всех слоев, что не согласуется с геологопалеонтологическими данными. В самом деле, если фациальные условия при накоплении отдельных слоев сланца и известняковых прослоев были различными, то это не могло не повлиять на структуру органического вещества отдельных слоев кукерсита, даже при том условии, что основная масса аллохтонного органического вещества, приносимая в бассейн осаждения, имела аналогичную химическую структуру $\left[{ }^{5,6}\right]$.

В целях выяснения этого геохимически важного вопроса было проведено комплексное исследование органического вещества сланцев отдельных слоев по стратиграфическому разрезу в пробах, отобранных в шахте «Сомпа». В данном сообщении приведены результаты исследований слоев $A, B, D$ и $E$, не подвергавшихся обогащению физическими методами, позволяющими извлекать максимально $85-88 \%$ керогена от потенциала. При этом остающийся с минеральной частью кероген явно относится к более насыщенной водородом части [7].

Ступенчатое окисление щелочным перманганатом калия дебитуминированных сланцев (спирт-бензол $1: 1$ ) указанных слоев, обработанных при комнатной температуре $3 \%$-ной соляной кислотой для разложения карбонатов кальция, проводилось при $50^{\circ} \mathrm{C}$ (табл. 1).

Из данных табл. 1 следует, что различия в элементарном составе между исследованными слоями находятся в пределах ошибок анализа.

Для окисления навески сланца с содержанием 100 г углерода суспендировались в $0,5 \Omega$ воды. Заданная навеска перманганата калия растворялась в водном растворе щелочи с таким расчетом, чтобы после введения суспензии был получен $1 \%$-ный раствор щелочи. До введения 
Таблица 1

Характернстика сланца отдельных слоев после обработки $3 \%$-ной соляной кислотой, вес. $\%$

\begin{tabular}{|c|c|c|c|c|c|c|c|}
\hline \multirow[b]{2}{*}{ Слой } & \multirow[b]{2}{*}{$\mathrm{A}^{\mathrm{c}}$} & \multirow{2}{*}{$\mathrm{SO}_{4}^{-2}$} & \multirow{2}{*}{$\begin{array}{l}\text { Органи- } \\
\text { ческое } \\
\text { вещество }\end{array}$} & \multicolumn{4}{|c|}{ Элементарный состав по [ [8] } \\
\hline & & & & $\mathrm{C}$ & $\mathrm{H}$ & $\mathrm{N}$ & $\begin{array}{l}\mathrm{O}+\mathrm{S}+\mathrm{Cl} \\
(\text { разность) }\end{array}$ \\
\hline $\begin{array}{l}A \\
B \\
D \\
E\end{array}$ & $\begin{array}{l}32,9 \\
24,0 \\
51,7 \\
30,7\end{array}$ & $\begin{array}{l}0,83 \\
0,75 \\
0,45 \\
0,80\end{array}$ & $\begin{array}{l}66,7 \\
75,8 \\
46,8 \\
68,9\end{array}$ & $\begin{array}{l}75,4 \\
75,9 \\
75,8 \\
74,5\end{array}$ & $\begin{array}{l}9,2 \\
9,1 \\
9,6 \\
9,6\end{array}$ & $\begin{array}{l}0,30 \\
0,29 \\
0,36 \\
0,29\end{array}$ & $\begin{array}{l}15,10 \\
14,71 \\
14,24 \\
15,61\end{array}$ \\
\hline
\end{tabular}

суспензии раствор окислителя подогревался на первой ступени до $48^{\circ}$, на последующих - до $50^{\circ}$. Суспензия добавлялась в окислитель при интенсивном перемешивании. Заданная температура поддерживалась подогревом или добавлением льда в водяную баню. Всего проведено 10 ступеней окисления, продукты которых изучены в трех этапах (табл. 2).

Как видно из табл. 2, на этапе $a$ существенных различий между слоями не отмечено, а на этапе 6 начиная с 4-й ступени слой $B$ окисляется медленнее, чем $A, D$ и $E$, т. е. он более устойчив к окислителю, чем другие. Разницы в стабильности структуры керогенов к окислителю еще больше проявляются на последующих ступенях окисления (этап 8 ). Поведение керогенов в процессе окисления показывает, что их строение неодинаковое. Особенно это становится заметным по мере углубления окислительно-гидролитической дест-

рукции основной структуры.

Продукты окисления после отделения нерастворимого остатка и определения в отдельных пробах выхода углерода в виде $\mathrm{CO}_{2}$ по схеме, приве-

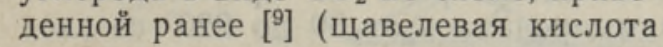
выделялась в виде оксалата кальция и определялась титрованием перманганатом натрия), подкислялись и разделялись на следующие фракции: 1) эфирный экстракт нерастворимых в кислой среде; 2) остаток нерастворимых в кислой среде и эфире; 3) эфирный экстракт кислого раствора; 4) эфирный экстракт сухого остатка растворимых в кислой среде; 5) ацетоновый экстракт сухого остатка растворимых в кислой среде.

У продуктов окисления по этапам $a, \sigma, в$ для всех исследованных слоев определены элементарный состав, кислотное число и молекулярная масса. На рис. 1 приведено распределение окисленного углерода в продуктах окисления. Видно, что при одинаковом расходе окислителя окисленный углерод распределяется по отдельным слоям различно.

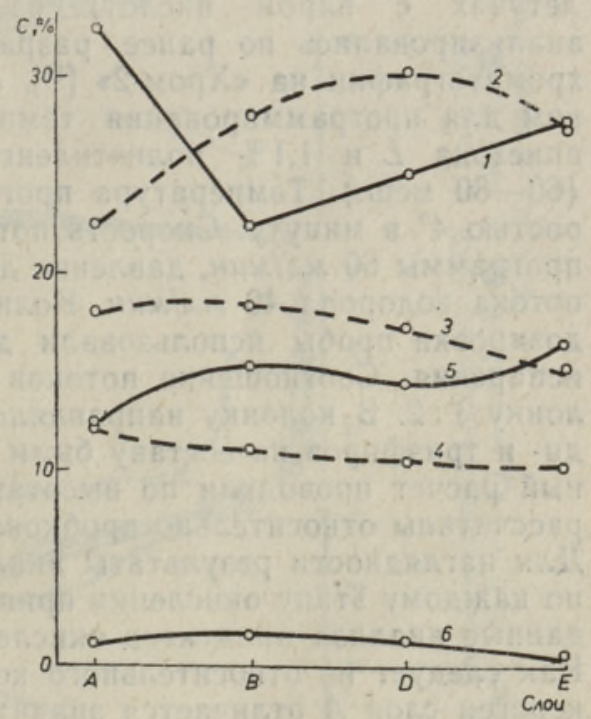

Рис. 1. Распределение окисленного углерода по слоям. 1 - остаток нерастворимых в эфире и кислой среде, 2 - эфирный экстракт нерастворимых в кислой среде, 3 - эфирный экстракт растворимых в кислой среде, 4 - щавелевая кислота, 5 - двуокись углерода, 6 - летучие с водяным паром кислоты. 
Окисление керогена кукерсита разных слоев при $50^{\circ} \mathrm{C}$

\begin{tabular}{|c|c|c|c|c|c|c|}
\hline \multirow{2}{*}{ Этапы } & \multirow{2}{*}{ Ступени } & \multirow{2}{*}{$\begin{array}{c}\text { Окислитель, } \\
2\end{array}$} & \multicolumn{4}{|c|}{$\begin{array}{c}\text { Время до обесцвечивания окислителя, } \\
\text { мин }\end{array}$} \\
\hline & & & A & $B$ & $D$ & $E$ \\
\hline$a$ & $\begin{array}{l}1 \\
2\end{array}$ & $\begin{array}{c}100 \\
50 \\
\text { Удаление } \\
\text { двуокиси } \\
\text { марганца }\end{array}$ & $\begin{array}{l}15 \\
16\end{array}$ & $\begin{array}{l}22 \\
25\end{array}$ & $\begin{array}{l}17 \\
18\end{array}$ & $\begin{array}{l}12 \\
15\end{array}$ \\
\hline 6 & $\begin{array}{l}3 \\
4 \\
5\end{array}$ & $\begin{array}{c}50 \\
50 \\
50 \\
\text { Удаление } \\
\text { двуокиси } \\
\text { марганца }\end{array}$ & $\begin{array}{l}22 \\
25 \\
30\end{array}$ & $\begin{array}{l}25 \\
45 \\
50\end{array}$ & $\begin{array}{l}23 \\
30 \\
40\end{array}$ & $\begin{array}{l}20 \\
25 \\
30\end{array}$ \\
\hline B & $\begin{array}{r}6 \\
7 \\
8 \\
9 \\
10\end{array}$ & $\begin{array}{l}30 \\
30 \\
30 \\
30 \\
30\end{array}$ & $\begin{array}{r}25 \\
45 \\
50 \\
70 \\
160\end{array}$ & $\begin{array}{r}50 \\
80 \\
95 \\
120 \\
160\end{array}$ & $\begin{array}{l}40 \\
55 \\
65 \\
90 \\
90 \\
\end{array}$ & $\begin{array}{r}25 \\
55 \\
70 \\
100 \\
135 \\
\end{array}$ \\
\hline
\end{tabular}

Углерод в

продуктах

окисления,

$\%$

$80,6 \quad 74,6 \quad 76,1$

80,6

Эфирные экстракты растворимых в кислой среде (после отделения летучих с паром кислот) в виде полных метиловых эфиров анализировались по ранее разработанной методике газо-жидкостной хроматографии на $\propto$ Хром- $2 »\left[{ }^{10}\right]$, снабженном нестандартным устройством для программирования температуры. Колонка 80/0,3 см с $3,8 \%$ апиезона $L$ и $1,1 \%$ полиэтиленгликольдистеарата на хромосорбе $W$ (60-80 меш.). Температура программировалась от 50 до $220^{\circ}$ со скоростью $4^{\circ}$ в минуту. Скорость потока газа-носителя (гелия) в начале программы $60 \mathrm{M} /$ мuн, давление до программирования 0,5 ати, скорость потока водорода $40 \mathrm{M} / \mu и н$. Количество пробы 0,15 мкл. Для точной дозировки пробы использовали делитель потока газа-носителя после испарения. Соотношение потоков газа-носителя через делитель и колонку $1: 2$. В колонку направлялось 0,05 мкл пробы. Эталонные смеси ди- и триэфиров по составу были близки анализируемым. Количественный расчет проводили по высотам пиков. Поправочные коэффициенты рассчитаны относительно пробковой кислоты - внутреннего стандарта. Для наглядности результаты анализа дикарбоксильных кислот (ДКК) по каждому этапу окисления приведены на рис. 2, где приведены также данные анализа продуктов окисления керогена сланца слоя $B$ при $20^{\circ}$. Как следует из относительного компонентного состава ДКК этапа $a$, кероген слоя $A$ отличается значительным содержанием низших кислот, в особенности С. Для остальных слоев состав ДКК практически одинаковый. Это может быть обусловлено тем, что перифернйная часть макромолекул керогена слоев $B, D$ и $E$ имеет сходное строение. С углублением окисления на этапах $\sigma$ и в различия в составе ДКК между отдельными слоями становятся более заметными. В составе ДКК керогена слоев $A, D$ и $E$ до конца окисления содержатся значительные количества ДКК $\mathrm{C}_{4}, \mathrm{C}_{5}$. В продуктах окисления керогена слоя $B$ заметно преобладает ДКК $\mathrm{C}_{7}$, несмотря на то что первичные продукты деструкции керогена 


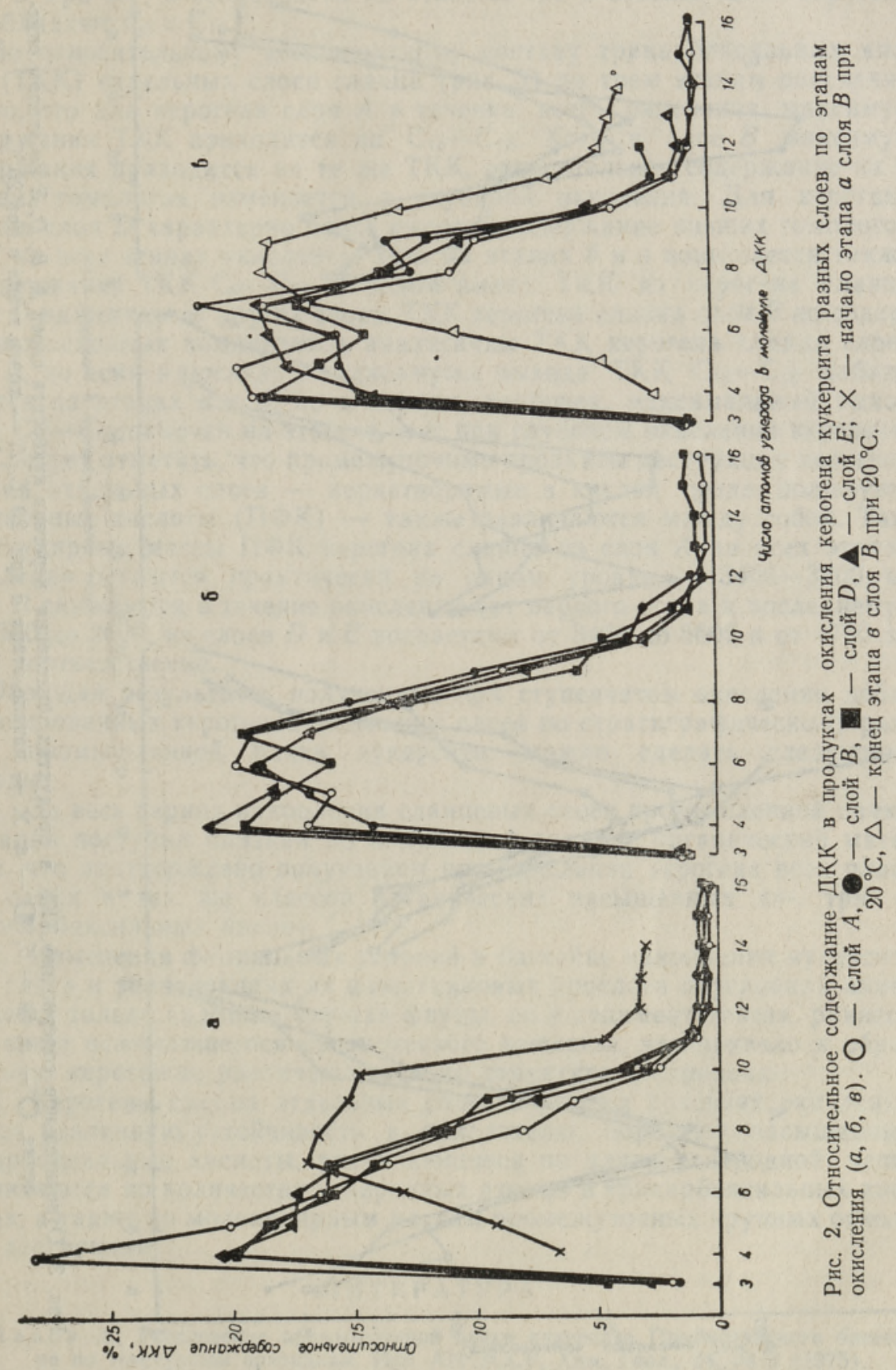



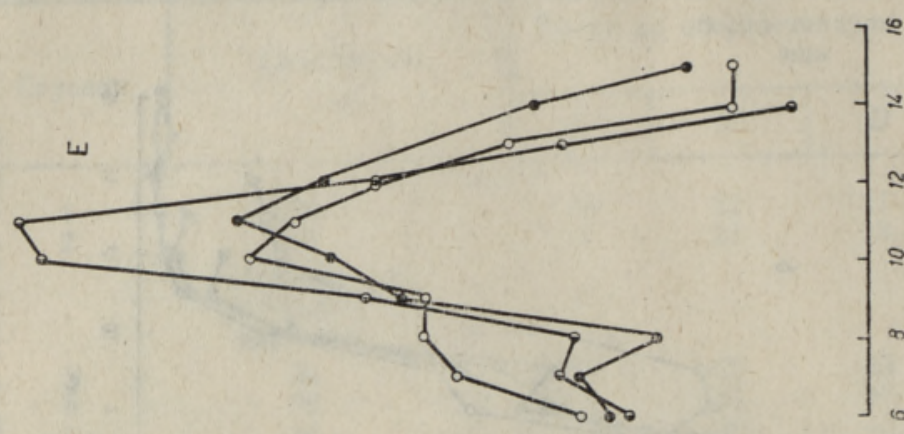

홍

c
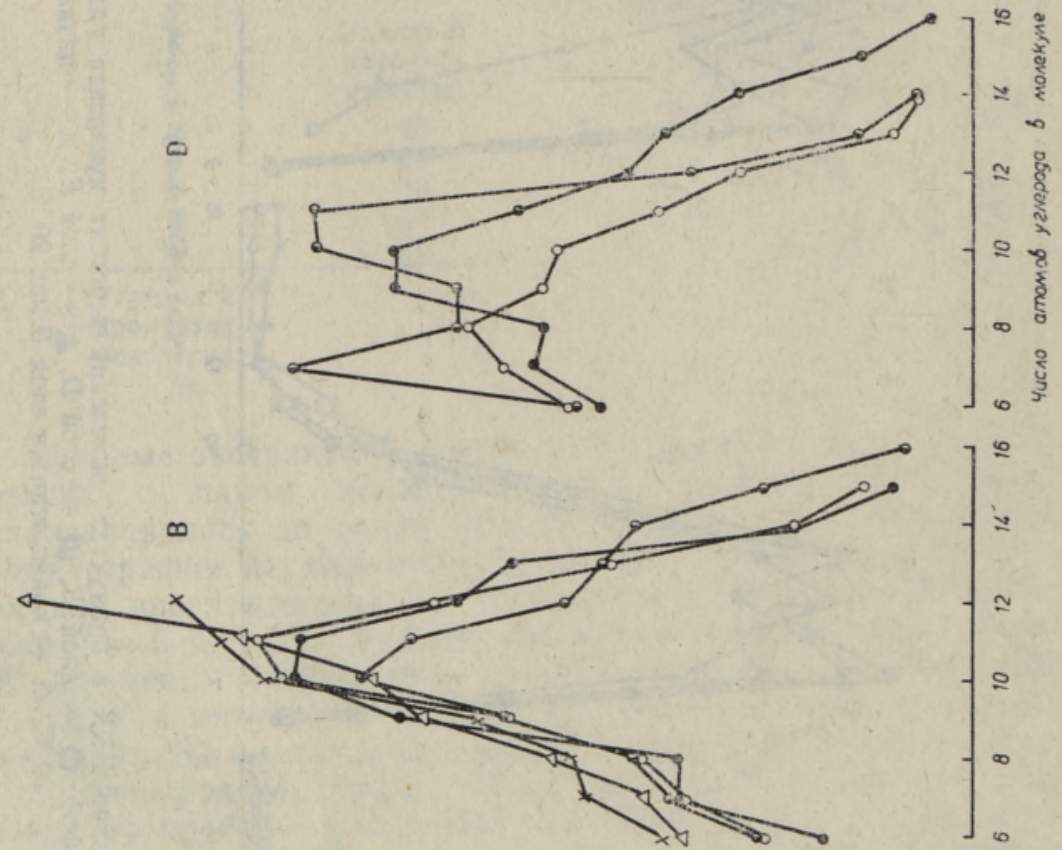

क

을

๘

鬲

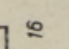

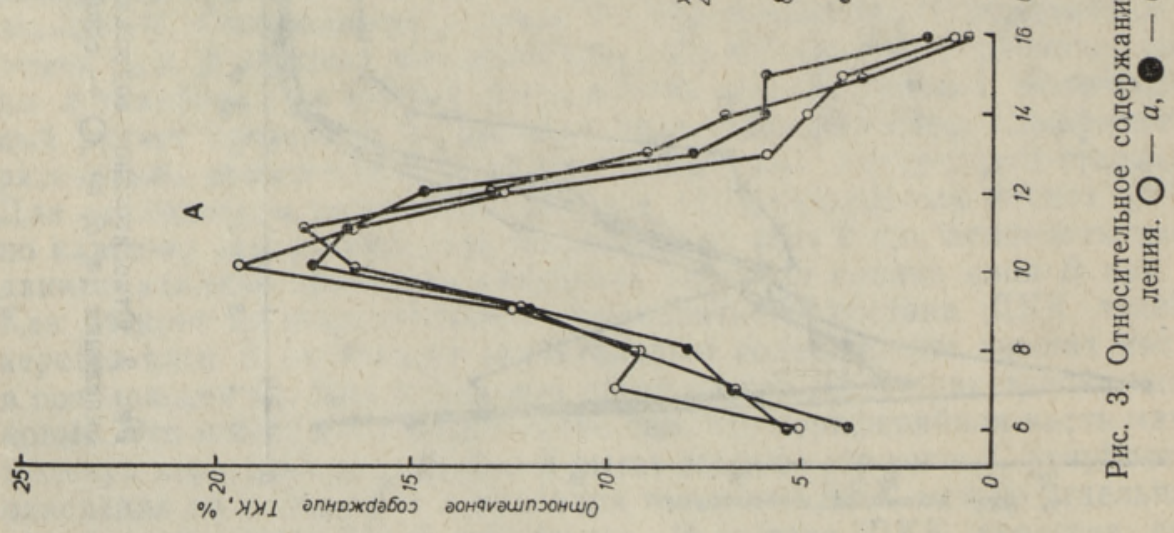


этого слоя имели наиболее длительный контакт с окислителем, и следовательно, их компонентный состав должен был бы обогатиться (более других) низшими гомологами: Укорочение углеродных цепей кислот, несомненно, происходило. Это видно и по кривым окисления керогена слоя $B$ при $20^{\circ}$, в особенности на этапе 6 , где в составе ДКК керогена преобладают $\mathrm{C}_{9}$ и $\mathrm{C}_{10}$.

По относительному компонентному составу трикарбоксильных кислот (ТКК) отдельных слоев сланца (рис. 3) по трем этапам окисления видно, что для керогена слоя $A$ в течение всего окисления максимум содержания ТKК приходится на $\mathrm{C}_{10}-\mathrm{C}_{12}$. Хотя в слое $B$ максимум содержания приходится на те же ТKК, относительное содержание их и высших гомологов изменяется с глубиной окисления. Для керогена сланца слоя $D$ характерно более высокое содержание низших гомологов TKК на всех этапах окисления, хотя на этапах 6 и в повышается также и содержание $\mathrm{TKK}_{9}-\mathrm{C}_{12}$. В целом выход. ТKК из керогена сланца слоя $D$ ниже, чем из других слоев. ТКК керогена сланца слоя $E$ по содержанию основных компонентов аналогичны ТKК керогена сланца слоев $A$ и $B$, но если в последних максимумы выхода TKK $C_{10}-C_{12}$ наблюдаются на этапах $a$ и $б$, то в первом, наоборот, максимальный выход TKK $\mathrm{C}_{11}-\mathrm{C}_{12}$ отмечен на этапе 8 , т. е. при глубоком окислении керогена.

Следует отметить, что промежуточные продукты деструкции керогена сланца отдельных слоев - нерастворимые в кислой среде полифункциональные кислоты (ПФК) - также различаются между собой. Так, молекулярные массы ПФҚ керогена сланца из слоя $A$ на всех этапах окисления остаются практически на одном уровне $-3400-3800$, из слоя $B$ снижаются в течение окисления (от первого этапа к последнему) от 3300 до 2600 , из слоев $D$ и $E$ возрастают от 3400 до 5600 и от 4700 до 5600 соответственно.

Обобщая результаты, полученные при ступенчатом окислении дебитуминированных керогенов отдельных слоев по стратиграфическому разрезу промышленной пачки кукерсита, можно сделать следующие выводы:

1. За весь пернод накопления сланцевых слоев промышленной пачки в осадки поступал близкий по химической природе органический материал, что подтверждено получением при окислении керогена всех пластов одних и тех же классов органических насыщенных ди-, три- и монокарбоксильных кислот.

2. Изменения фациальных условий в бассейне накопления кукерсит ных слоев и разделяющих их известняковых прослоев обусловили изменение не только видового состава фауны, но и седиментогенеза, раннего диагенеза осаждавшегося органического вещества, что привело к образованию керогенов, различающихся по структуре и строению.

3. Керогены сланца отдельных слоев в равных условиях окисления имеют различную устойчивость к окислителю, образуют насыщенные дикарбоксильные кислоты, различающиеся по длине углеродной цепи, различаются по количеству углеродных атомов в трикарбоксильных кислотах, а также по молекулярным массам промежуточных крупных осколков деструкции.

\section{ЛИТЕ Р А Т У Р А}

1. А алоэ А., Расчленение промышленной пачки кукерсита Прибалтийского бассейна по текстурным признакам. Изв. АН ЭССР, Хим. Геол., 24, № 3 (1975).

2. L i nd e n be i n, H. A. R., Arh. Sci. phys. natur., 3 (1921), Geneve; Chem. Zbl., Bd. 3, N 17 (1921).

3. Р аудсепп Х. Т., Фомина А. С., Торпан Б. К., Норман Х. К., Тр. Таллинск. политехн, ин-та, сер. А, № 57 (1954). 
4. Т о р п а н Б. К., Тр. Таллинск, политехн. ин-та, сер. А, № 57 (1954).

5. М янниль Р. М., История развития Балтийского бассейна в ордовике. Таллин, 1966.

6. Прогноз горючих сланцев Европейской части СССР. Таллин, 1974.

7. Фомина А. С., Д егтерев а 3. А., Горючие сланцы. Химия и технология, вып. 2, Таллин, 1956.

8. Р а удс еп п Х., О методе определення органической массы прнбалтийскнх сланцев. Тр. Таллинск. политехн. ин-та, сер. А, № 53 (1950).

9. Побуль Л. Я., Мянник А. О., Фомнна А. С., Иконописпева О.А., Химия твердого топлива, № 3 (1974).

10. Мянник Э. И., Фомина А. С., М янник А. О, Иконописцева О. А., Э р м А. Ю., Химия твердого топлива, № 6 (1972).

Институт химии
Академии наук Эстонской ССР

Поступила в редакцию 10/IX 1976

Linda POBUL, A. MANNIK,

A. FOMINA, Saima SALUSTE

\section{KUJUNEMISAEGSETE FATSIAALSETE MUUTUSTE MOJUST KAEVANDATAVATE KUKERSIIDIKIHTIDE KEROGEENI STRUKTUURILE}

Artiklis on esitatud kukersiidi A-, B-, D- ja E-kihi kerogeeni uurimise tulemused. Kerogeeni oksüdeeriti astmeliselt kaaliumpermanganaadi leeliseses vesilahuses. Leiti, et ühesugustes destruktsioonitingimustes tekkinud küllastunud di- ja trikarboksüülhapetel ning oksüdatsiooni vaheproduktidel on uuritud kihile iseloomulik küllastunud süsinikahela pikkus ja keskmine moolmass. On tehtud järeldus, et eri kihtide kerogeenid erinevad omavahel nii struktuuri korrapärasuse kui ka määratud alifaatsete fragmentide kvantitatiivse koostise poolest.

Linda POBUL, A. MANNIK, A. FOMINA, Saima SALUSTE inis

\section{VON DER EINWIRKUNG DER FAZIALEN VERANDERUNGEN IM ENTSTEHUNGSGANGE DER ABZUBAUENDEN KUKERSITSCHICHTEN AUF DIE STRUKTUR DES KEROGENS}

Der Artikel bringt die Untersuchungsergebnisse des Kukersit-Kerogens der Schichten A, B, D und E. Kerogen ist stufenweise in einer basischen Wasserlösung des Kaliumpermanganats oxydiert worden. Es wurde festgestellt, daB die in identischen Destruktionsbedingungen entstandenen saturierten di- und tri-Karboxylsäuren sowie die Oxydationszwischenprodukte der betreffenden Schichten die charakteristische Kettenlänge und die durchschnittliche Molekülmasse aufweisen. Es ergibt sich, daB das Kerogen, was die strukturelle RegelmäBigkeit und die quantitative Zusammensetzung der bestimmten aliphatischen Fragmente anbetrifft, in allen untersuchten Schichten unterschiedlich ist. 